\title{
Extraction and dehydration of millet milk powder for formulation of extruded product
}

\author{
M.Pushpa Devi ${ }^{* 1}$ and Narayanasamy Sangeetha ${ }^{2}$ \\ Research Scholar ${ }^{1}$ and Assistant Professor ${ }^{2}$ \\ Department of Food Science and Technology, Pondicherry University.
}

\begin{abstract}
Millet is a minor cereal possessing high nutritional value but its consumption is limited which is mainly due to the lack of ready-to-cook or ready-to-eat millet products. It is suggested that processing of millet to prepare RTC foods may increase its economic and nutritional value. The present study clearly focuses on the utilization of under exploited millets which are good source of energy, proteins and minerals responsible for maintaining healthy blood sugar levels. It is also high in starch content which is a desirable property for extrusion cooking. Composite millets milk powder prepared with the combination of finger millet (Eleusine coracana) and pearl millet (Pennisatum glaucum) were utilized for preparation of RTC extruded product. The techniques used for processing the millet milk powder are soaking and extraction of milk from millets, dehydration and milling. The physical and functional properties of the composite millet powder were analyzed. The result of the composite millet powder and maida (control) indicated that the bulk density was ranging from 1.02 to $0.68 \mathrm{~g} \mathrm{~cm}^{-3}$ while swelling index varied between 3.46 and 3.87 and the water holding capacity of the maida (control) and millet milk powder varied from $0.9 \%$ to $0.93 \%$ which was suitable for quality extrusion. The mean scores of organoleptic evaluation showed that the extruded products prepared with the ratio of 50:50 of composite millet powder and maida (7.18) were within the acceptable range in all parameters which produced the most acceptable RTC extruded product in terms of nutrient content, color, texture and cooking quality and sensory characteristics. Therefore the results suggest that the investigated cereal processing technologies could be successfully applied to millets to prepare RTC or use products, and thereby increasing its availability, utilization and thereby consumption.
\end{abstract}

Keywords: Ready-to-cook; extrusion; cooking quality; finger millet; pearl millet.

\section{Introduction}

Millet is considered as a highly palatable and good source of energy, protein and minerals. Millet is the fifth most important cereals in the world ranging from wheat, maize, rice and barley (Shayo et al, 2001). The grains were used for traditional as well as is being used for novel foods. These grains were established to exhibit beneficial effects on cholesterol levels, because of its high dietary fiber and phytochemical content. The value addition of food has assumed significant importance in the last decade due to some socio-economic and industrial factors. Ready -to- cook extruded product has dramatically transformed the cereal industry, the key thing being quality extruded products offered to consumer at competitive price. Now day's ready - to- cook products plays an important role of daily nutrient and calorie intake of many consumers. Ready -to- cook extruded products are generally made from corn, wheat, rice and oats, while other cereals such as pearl millet, finger millet, barley, rye sorghum have not been used extensively. Therefore, it becomes important to focus on promoting maximal use of locally available inexpensive foods rich in protein, calcium, iron, fiber etc (Barrett $\mathrm{AH}$ et al, 1992). In order to produce good quality flour and to overcome cumbersome and time-consuming food preparation of millets, ready-to-cook and convenient food process should be developed. Ready-to-cook millet based extruded products made by adopting traditional processing methods gives you a healthful addition for a better lifestyle. The Pearl millet and finger millet could seek great potential as an ingredient in extruded breakfast cereals because of its lower cost. In order to intensify the significance of the underutilized millets in role of health the specific following objectives was focused to develop a process for millet milk powder and ready to cook extruded product and to evaluate the quality characteristics of developed composite millet powder and product.

\section{Materials and methods}

2.1. Preliminary preparation of sample: Finger millet (Eleusine coracana) and pearl millet (Pennisatum glaucum) were procured from the super market in Pondicherry. Both the millets were cleaned manually to remove broken seeds, dust and other extraneous materials. The techniques which were used for processing millets are soaking, extraction of milk from millets; dehydration and milling. The extruded product made from maida served as a control. 


\subsection{Process involved in extraction of milk from processed millets}

After the preliminary processing, the finger millet and pearl millet (composite millets 1:1) were soaked in water overnight for a period of $12 \mathrm{hrs}$. Then the soaked millets were processed further for grinding and extraction of milk. The schematic representation of steps involved in the extraction of milk is given in Figure 1.

2.3. Dehydration process: The extracted milk w a dehydrated by using hot air oven at temperature range of $70^{\circ} \mathrm{c}$ to $80^{\circ} \mathrm{c}$ for a period of $8 \mathrm{hrs}$. The dehydrated millet milk was milled to fine powder. Finally the acquired composite mix with the combination of finger millet milk powder $(50 \mathrm{~g})$ and pearl millet milk powder $(50 \mathrm{~g})$ is stored in suitable packaging material for further analysis.

\subsection{Processing of extruded product from composite millet milk powder}

"Extrusion" is a process, create objects for a fixed cross-sectional profile. A material is pushed or drawn through a die of desired cross-section. The two main advantages of this process over the other manufacturing processes are, it has the ability to create very complex cross-sections and work materials are brittle, because the material only encounters compressive and shear stresses. It will also form an excellent surface finish (Oberg P 2000). The extrusion was carried out by cold extrusion with single screw extruder (La Monferrinasrl Model dolly) at a pressure of $400 \mathrm{rpm}$. After several permutation and combination the ratio of three different millet milk powder and Maida was developed for the extrusion of pasta, $1.6 \mathrm{~g}$ of guar gum was added as a binding agent to the $100 \%$ of the composite millet milk mix. The ratio of composite millet powder is given in table 1 . The extruded pasta was dried at $60^{\circ} \mathrm{c}$ in hot air oven for 2 hours. The step involved in the processing of extruded product from composite millet powder is given in figure 2 .

\subsection{Quality characteristics of composite millet powder and extruded product}

\subsubsection{Physical properties of composite millet powder}

The millet milk powder was analyzed for bulk density( Okaka JCet al,1979), water holding capacity(Beuchat LR 1977), Foam capacity and foam stability (Narayana et al,1985) and swelling index (Leach $\mathrm{H} \mathrm{W}$ et al,1985 ) as per the standard procedures.

\subsubsection{Amino acid analysis}

The composite millet powder and maida were analyzed for the amino acid composition using HPLC (lachrome hitachi.), The samples were hydrolyzed at $110{ }^{\circ} \mathrm{C}$ with $6 \mathrm{M} \mathrm{HCl}$. Separations were attained with a 4.6 $\mathrm{mm} \times 150 \mathrm{~mm}$ (cat no. den-5c18-15046) using a binary gradient system with $25 \mathrm{~mm}$ potassium phosphate, ph as 3.3 and acetonitrile. The coloum was maintained at ambient around $23^{\circ} \mathrm{c}$ and detected at $254 \mathrm{~nm}$ sample. Five microlitre of aminoacids standards mixture was run as standard reference. Amino acid composition was expressed as grams for amino acid per 100g of flour.

\subsubsection{Morphology of millet granules}

The morphology of composite millet powder and maida granules was evaluated by scanning electron microscope (SEM) (QUANTA FEG 250 ESEM). Samples were mounted on circular aluminum stubs with double-sided sticky tape. The particle granules were evenly distributed on the surface of the tape. Then the samples were coated with $12 \mathrm{~nm}$ gold, examined and photographed at an accelerating voltage of $5 \mathrm{kv}$ with a magnification of $\mathrm{x} 1000$ and $\mathrm{x} 5000$.

\subsubsection{Cooking Quality}

Cooking time, Cooking loss and Water Absorption:

The cooking time for the pasta samples was estimated according to AACC method (AACC 2005). Cooking loss was determined according to the Bureau of Indian Standards (BSI 1976).

\subsection{Sensory analysis}

The developed product was served to a panel member for the evaluation of the product based on its flavor, color, texture, taste, Appearance, Mouth feel and over all acceptability using Nine-point hedonics scale( $1=$ dislike extremely) $(9=$ like extremely).From the scores of the sensory evaluation the best one was been selected among the three different variations. It was found that the product developed from composite millet powder (50:50) was been highly preferred by the panelists which was finalized for further evaluation of its quality characteristics.

\subsection{Color measurement}

Colour $\left(L^{*}, a^{*}, b^{*}\right)$ values of the samples was determined by using Hunter Colour Flex Meter. $L^{*}$ is Known as the lightness and extends from 0 (black) to 100 (white). The other two coordinates $\mathrm{a}^{*}$ and $\mathrm{b}^{*}$ 
represent redness $(+a)$ to greenness $(-$ a) and yellowness $(+b)$ to blueness $(-b)$, respectively were recorded. Three measurements were taken for each sample and their means were reported.

\subsection{Moisture}

The initial and final moisture content of the product was measured using moisture meter. The initial moisture was measured as soon as the product comes out from extruder. The final moisture was measured after drying the product in the hot air oven around $60^{\circ} \mathrm{c}$ for $2 \mathrm{hrs}$.

\subsection{Texture}

The texture is an important quality characteristic of extruded products. The parameters such as stickness and hardness were analyzed for the developed extruded product using texture analyser (Modelno.5197, stable micro system, HD plus, Goldalming, survey, GU71YL, UK. Probe HDP/PFS.

\subsection{Nutrient analysis of extruded product}

The developed extruded product was analyzed for protein by kjedhal method (Prabhasankar P et al 2006b), carbohydrate by using anthrone method (AOAC 2000), fat by soxhlet extraction method (Ranganna $\mathrm{S}$ 2000), iron, ash (AOAC 2000) and moisture (AOAC 2000) was done using standard procedures.

\subsection{Compilation of data}

All analysis was carried out in triplicate. Statistical analysis was carried out by using statistical tool SPSS. The data was subjected to ANOVA. The significance of mean differences was determined by Least Significant Difference (LSD) method.

\subsection{Physical properties of composite millet powder}

\section{Results and Discussion}

The physical properties of composite millet powder are shown in table (2). The swelling power of the composite millet powder was found to be 3.87 . However the control (maida) was found to be 3.46 which was more or less similar $(p \leq 0.05)$. This is because millet also possess good amount of starch equal to maida. Hence the composite millet powder also holds the characteristics of extrusion property as the maida does. The high swelling power may lead to starch gelatinization and degradation during extrusion process (Karuna D et al,1996).Hence it is more appropriate for the extrusion.

The water holding capacity (WHC) of control (maida) and composite millet powder was found to be 0.93 and 0.9 respectively which was almost similar. The increase in WAI was attributed to higher proportion of gelatinized starch granules and maximum WAI indicated complete gelatinization (Wilhelm LR et al, 2004). From the above results it shows that the composite millet powder was more hydrophilic due to higher protein and carbohydrate content (Table 2).

Food is an important aspect in determining the packaging requirement, material handling and application in wet processing in food industry (Yasumatsu K et al,1972). As shown in Table 2, the bulk density of control (maida) and composite millet powder was found to be 1.02 and 0.68 respectively. Increased gelatinization increases the volume of extruded product consequently the bulk density decreases as observed in this work(Harris P.Let al,1988). The density of processed products indicates the characteristics of the container the package product density influences, the amount and strength of packaging material, texture and the mouth feel (Mbithi-Mwikya S et al,(2000).

The results of the foam capacity and foam stability of the powder samples are shown in table 2 . Composite millet powder recorded the highest foaming capacity of $98 \%$ while the control (maida) flour has only $95.96 \%$. The foam formation and stability are key functions of the different type of protein, $\mathrm{pH}$, processing methods, viscosity and surface tension. But in the case of foam stability the composite millet powder $(5.23 \%)$ shows higher level when compared to control sample (2.4\%).

\subsection{Amino acid composition of millet powder}

The protein in pasta was considered to be incomplete because it was lacking in one or two of the essential amino acids. The protein in extruded product is low to medium depending on the type of powder. Most of the extruded product is made from durum wheat which contains both protein and gluten. The amino acid composition of composite millet powder and control (maida) are presented in Table 9. The total amount of essential amino acids composition and the concentration are ranged between $0.88-0.20 \mathrm{~g} / 100 \mathrm{~g}$ of composite millet powder and $0.76-0.08 \mathrm{~g} / 100 \mathrm{~g}$ of control (maida). The highest concentration of conditionally essential amino acids for the composite millet powder was threonine while the least was valine. Finger millet contains 44.7\% essential amino acids (FAO (1991) of the total amino acids which is higher when compared with the reference protein $(33.9 \%)$ of FAO (FAO (1968). Tryptophan is usually considered as the second most deficient 
amino acid in cereals; however it is not deficient in finger millet (Ravindran G 1992). Among the millets, finger millet is relatively better balanced in essential amino acids because it contains more lysine, thereonine and valine (Lupien JR (1990). The isoleucine content of finger millet is also high. The mean values of the amino acids profile from this study revealed that most of the essential amino acids are present in adequate amount when compared with the recommended values of $\mathrm{FAO} / \mathrm{WHO} / \mathrm{UNU}$ (2007).

\subsection{Morphology of millet starch granules}

The scanned electron micrograph of the particle size is presented in Figure 3. The shape of the particles varies like oval, round and hexagon. The shape of particles size in composite millet powder appeared as different geometrical shapes. But in the control (maida) the shape and size was uniform. The granule size of maida $(2-4 \mu \mathrm{m})$, was bigger than the millet granule starches $(3-6 \mu \mathrm{m})$, such as rice starch $(3-8 \mu \mathrm{m})$, sorghum starch $(4-24 \mu \mathrm{m})$ and wheat starch $(2-38 \mu \mathrm{m})$. In Figure 3, the surfaces of both the flour starch granules appeared to be smooth which indicates that the isolation process is efficient and it does not cause any damage to starch granules.

\subsection{Texture}

Textural parameters like cohesiveness and adhesiveness are the most important in cooking quality. Adhesiveness or stickiness is related with the amount of starch and starch gelatinization. In the early stages of cooking, adhesiveness values were found to be higher and it would be decreased as the cooking time was proceeded. Basically, when it is under the optimum cooking time region which is roughly around 12 min for each extruded product type the adhesiveness values are very low. Water cannot diffuse into inner layers in optimum cooking time and the protein network does not develop as a result of this starch leaches into cooking water easily. Cohesiveness is a good indicator for internal binding of extruded product during extrusion. It holds the product together while cooking. In the present study there was not much difference between the cohesiveness values of control and composite millet extruded product. An increase in cohesiveness is a desirable characteristic for maintaining integrity after processing (Cardoso MB et al2006). Hence the composite millet extruded product has more or less similar in textural properties when compared with control (maida).

\subsection{Color}

Color is an important quality parameter of pasta. It results from the desirable yellow component to the undesirable brown component. The units within the $L^{*}, a^{*}, b^{*}$ system give equal perception of the color difference to a human observer. The $\mathrm{L}^{*}, \mathrm{a}^{*}, \mathrm{~b}^{*}$ values of the composite millet extruded product with different ratio for maida are presented in Table 4 . The highest $\mathrm{L}^{*}$ values (brightness) were found with the control (maida) product. The extruded product prepared from composite millet powder in all ratio had the lowest L* values (light brownness), which can be explained by the higher content of ash and dietary fiber, $a^{*}$ values were negative (green direction) in all extruded product. The highest $b^{*}$ values were observed in control product. The composite millet extruded product prepared in ratio of 50:50 is similar in their $b^{*}$ values when compared to control during the sensory evaluation.

\subsection{Moisture}

The initial and the final moisture content of the pasta was given in table (7). The initial moisture content of the control and composite millet extruded product (50:50),(70:30),(90:10) was found to be 14.18 $\%, 24.81 \%, 21.56 \%$ and $22.25 \%$, and the final moisture content of pasta was found to be $5.63 \%, 6.1 \%, 6.4 \%$ and $6.9 \%$ respectively The maximum moisture content of pasta is $14.3 \%$ (dry basis). The minimum moisture content observed in the extruded product increases the shelf life as well.

\subsection{Cooking quality of extruded product}

The cooking quality of extruded product in different ratio of composite millet milk extruded product was compared with control product. The desired quality of cooked extruded product must be firm, resilient and non-sticky for maximum consumer acceptance. The cooking time of composite millet extruded product was increased when compared to the control product as it possesses high protein content. Onwulata C. I et al., (2001) observed that cooking time of the extruded product increased linearly with the protein content. The weight of the cooked sample was higher in composite millet extruded product when compared to control. But in the case of cooking loss the volume of gruel was lower in control when compared to millet extruded product. Among the various ratios used in the preparation of extruded product, ratio of 50:50 was well suitable for cooking.

\subsection{Sensory evaluation of pasta}

Mean scores of the sensory parameters and the total quality scores are shown in Table 3. Among the extruded product, the extruded product was prepared from composite millet powder in the ratio of 50:50 has the 
highest total sensory score (7.18) and they are significantly higher in their appearance (7.714), colour (7.15), flavour (6.75), texture (7.30), taste (6.90), mouth feel (6.76), and overall acceptability (7.18). The extruded product prepared from composite millet powder in the ratio of 90:10 had the lowest score when compared to composite millet extruded product in 50:50. The scores were found low in their external appearance due to brown color and decreased firmness when compared with the commercial control. It revealed that the scores of the overall acceptability of the composite millet extruded product and maida can be successfully mixed to the level of 50:50 respectively to produce a better acceptable product. The overall acceptability of composite millet extruded product had highest significant increase in the sensory scores when compared with control.

\subsection{Nutrient analysis of extruded product}

The nutrient analysis was performed for the extruded product which scores higher in sensory evaluation among the panelist. The nutrient content of extruded product made from composite millet powder were compared with control (maida) pasta was shown in table 8.The result depicts that, there was an increased protein, fat, ash, dietary fibre, iron and calorific value content when compared to control. But the carbohydrate content was decreased when compared to the control (68.3). The fibre content was nil in control (maida) pasta whereas composite millet extruded product contains $1.9 \mathrm{~g}$ of fibre.

The second major component of millet is protein. Finger millet has nearly 7\% protein but large variations in protein content from 5.6 to $12.70 \%$ have been reported by Bhatt et al.,(2003). In the present study the protein content of composite millet extruded product $(7.37 \mathrm{~g})$ seems to be higher when compared with the control (5.14g). There is an increase in the iron content of composite millet extruded product (1.5), since it contains finger millet which is a good source of iron. Calorific value in the composite millet extruded product (335) is slightly higher when compared to control (293), this is due to its increase in protein and fat content. Jonnalagadda et al (2011) explain that the millet is the rich sources of carbohydrate, protein, fat, vitamins, minerals, and fiber. When compared with the control (maida), the composite millet milk extruded product possess significantly $(p<0.05)$ higher nutrient content among the samples.

\section{Conclusion}

Extrusion cooking is one of the contemporary food processing technologies applied for preparation of variety of ready to cook foods, snacks, specialty and supplementary foods. Foods are meant not only to satisfy hunger but also to provide essential nutrients and prevent nutrition related diseases and improve physical and mental well being of consumers. Thus the pasta formulated using composite mix could provide health benefits beyond its basic nutrition.

\section{References}

[1]. Shayo NB, Tiisekwa BPM, Laswai HS, Kimaro JR. Malting characteristics of Tanzania finger millet varieties. Food Nutri J. Tanzania, 2001,10:1-3.

[2]. Barrett AH, Peleg M . Extrudate Cell Structure-Texture Relationships. J Food Science 1992,57:1253-1257.

[3]. Oberg P. Co-extrusion: Recent developments using cooking Extruder. Cereal Foods World.2000, 32:816-819.

[4]. Okaka JC, Potter NN Physicochemical and functional properties of cowpea powders processed to reduce beany flavour. J. Food Sci. 197, 44: 1235-1240

[5]. Beuchat LR Functional and electro phoretic characteristics of succinylated peanut flour protein.J Agric Food Chem. 1977, 25:258 261 .

[6]. Narayana, Narasinga Rao Implications of antinutritional components in soybean foods.CRC Reviews Food Science and Nutrition. 1985,34:31-67.

[7]. Leach HW, McCowen LD, Schoch TJ. Structure of the starch granules. In: Swelling and solubility patterns of various starches. Cereal Chemistry. 1959, 36, 534-544.

[8]. AACC (2005). Approved Methods of the AACC, 11th Ed., American Association of Cereal Chemists, St. Paul, MN.

[9]. Prabhasankar P, Ganesan P, and Bhaskar N. Influence of Indian brown seaweed (Sargassummarginatum) asan ingredient on quality, biofunctional, and microstructure characteristics of pasta. Food Sci. Technol. Int. 2009b, 15: 471-479.

[10]. AOAC(2000).Official Methods of Analysis. Association of Official Analytical Chemists. Washington, DC, 16th Edition.

[11]. Ranganna S. Vitamins: In Hand book of Analysis and Quality Control for fruit and vegetable products. Second edition. Tata McGraw Hill publishing Co.ltd, New Delhi, 2000 pp113-117.

[12]. Adebowal KO, Lawal OS. Comparative study of the functional properties of bambara groundnut (Voandzeia subterranean), jack bean (Cana valiaensiformis) and mucuna bean (Mucuna pruriens) flour. Food Res Inter. 2004, 37: 355-365.

[13]. Karuna D, Noel G, Dilip K. Production and use of raw potato flour in Mauritanian traditional foods. Food \& Nutritional bulletin, 1996, 17: 12-14.

[14]. Wilhelm LR, Dwayna AS, Gerand HB ( 2004). Introduction to problem solving skills : In Food and Process Engineering Technology. ASAE.

[15]. Yasumatsu K, Sawada S, Moritaka M, Misaki J, Toda T, Wada K. Ishii. Agric Biol Chem. 1972, $36: 719$.

[16]. Harris, P.L., Cuppet, S.L. and Lee, K.W. A scanning electron microscope study

[17]. of maize gluten meal and soy extrudate. Cereal Chemistry .1988,65(2):228-232.

[18]. Mbithi-Mwikya S, Ooghe W, Van Camp J, Nagundi D, Huyghebaert A. Amino acid profile after sprouting, Autoclaving and lactic acid fermentation of finger millet (Elusine coracana) and kidney beans (Phaseolus vulgaris L.) J Agric Food Chem. 2000,48: 30813085 .

[19]. FAO (). Amino Acid Scoring Pattern: In Protein quality evaluation, FAO/WHO Food and Nutrition Paper. 1991, $12-24$. 
[20]. FAO). Cereal and Grain Products: In Food composition table for use in Africa. U.S. department of health, education and welfare, Bethesda MD 2001 and FAO, Rome, Italy. 1968,12-24.

[21]. Ravindran G . Seed proteins of millets: amino acid composition, proteinase inhibitors and in vitro digestibility. Food Chem. 1992, 44: 13-17.

[22]. Lupien JR). Sorghum and millets in human nutrition. FAO, ICRISAT. 1990,86.

[23]. Joint FAO/WHO/UNU) Expert Consultation on Protein and Amino Acid Requirements in Human Nutrition. WHO Technical Report Series No.935,2007.

[24]. Bhatt A, Singh V, Shrotria PK, Baskheti DC. Coarse Grains of Uttaranchal: Ensuring sustainable Food and Nutritional Security. Indian Farmer's Digest. 2003 34-38.

[25]. Onwulata, C. I., Smith, P. W., \& Konstance, V. H. Incorporation of whey products in extruded corn, potato of rice snacks.Food Research International, 2001, 34,679-87.

[26]. Jonnalagadda Satya S, Harnack Lisa. Putting the Whole Grain Puzzle Together: Health Benefits Associated with Whole Grain Summary of American Society for Nutrition 2010 Satellite Symposium. J of Nutrition. 2011, 141:1011-1022.

Table 1. Ratio of composite millet powder for extrusion

\begin{tabular}{lcl}
\hline Ratio & $\begin{array}{l}\text { Composite Millet } \\
\text { milk powder(\%) }\end{array}$ & $\begin{array}{l}\text { Maida } \\
(\%)\end{array}$ \\
\hline $\mathbf{5 0 : 5 0}$ & 50 & 50 \\
$\mathbf{7 0}: \mathbf{3 0}$ & 70 & 30 \\
$\mathbf{9 0}: \mathbf{1 0}$ & 90 & 10 \\
\hline
\end{tabular}

Table 2. Physical properties of composite millet powder

\begin{tabular}{|l|l|l|l|l|l|}
\hline Samples & $\begin{array}{l}\text { Swelling power } \\
(\mathbf{g} / \mathbf{g})\end{array}$ & $\begin{array}{l}\text { Water holding } \\
\text { capacity (\%) }\end{array}$ & $\begin{array}{l}\text { Bulk } \\
\text { density }\left(\mathbf{g} / \mathbf{c m}^{\mathbf{3}}\right)\end{array}$ & $\begin{array}{l}\text { Foam } \\
\text { Capacity }\end{array}$ & $\begin{array}{l}\text { Foam } \\
\text { Stability }\end{array}$ \\
\hline Control (maida) & $3.46 \pm .057^{\mathrm{a}}$ & $8.73 \pm .346^{\mathrm{a}}$ & $1.02 \pm .034^{\mathrm{a}}$ & $95.96 \pm .444^{\mathrm{a}}$ & $2.4 \pm 0.115^{\mathrm{b}}$ \\
\hline composite flour & $3.875 \pm 0.058^{\mathrm{ab}}$ & $0.84 \pm 0.005^{\mathrm{db}}$ & $0.68 \pm 0.17^{\mathrm{d}}$ & $98 \pm 0.011^{\mathrm{d}}$ & $5.23 \pm .635^{\mathrm{a}}$ \\
\hline
\end{tabular}

All values are means of triplicate determinations \pm standard deviation (SD)

Column followed by different letters are significantly different $(\mathrm{p}<0.05)$

Table 3.Sensory evaluation of extruded product

\begin{tabular}{|l|l|l|l|l|l|l|l|}
\hline Sample & Appearance & Color & Flavor & Texture & Taste & Mouth feel & $\begin{array}{l}\text { Overall } \\
\text { Acceptability }\end{array}$ \\
\hline Control & 6.66 & & & & & & 6.75 \\
\hline Composite millet milk extrude product & 6.63 & 6.7 & 6.54 & 6.30 & 6.38 & 7.18 \\
\hline $50: 50$ & 7.714 & 7.15 & 6.75 & 7.30 & 6.90 & 6.76 & 6.45 \\
\hline $70: 30$ & 6.625 & 6.27 & 6.46 & 6.25 & 6.3 & 6.38 & 6.61 \\
\hline $90: 10$ & 6.78 & 6.54 & 6.38 & 6.54 & 6 & 6.3 & \\
\hline
\end{tabular}

Table 4. Textural parameters of extruded product

\begin{tabular}{|l|l|l|}
\hline $\begin{array}{l}\text { Textural } \\
\text { parameters }\end{array}$ & Stickiness & Cohesiveness \\
\hline Control & $0.39 \pm 0.011^{\mathrm{ab}}$ & $0.83 \pm 0.006^{\mathrm{a}}$ \\
\hline $\mathbf{5 0 : 5 0}$ & $0.39 \pm 0.01^{\mathrm{ab}}$ & $0.85 \pm 0.006^{\mathrm{b}}$ \\
\hline $\mathbf{7 0 : 3 0}$ & $1.14 \pm 0.006^{\mathrm{c}}$ & $0.88 \pm 0.006^{\mathrm{c}}$ \\
\hline $\mathbf{9 0 : 1 0}$ & $1.76 \pm 0.006^{\mathrm{d}}$ & $0.90 \pm 0.005^{\mathrm{d}}$ \\
\hline
\end{tabular}

All values are means of triplicate determinations \pm standard deviation (SD)

Column followed by different letters are significantly different $(\mathrm{p}<0.05)$

Table 5. Color values of extruded product

\begin{tabular}{|l|l|l|l|}
\hline Sample & $\begin{array}{l}\text { Cooking } \\
\text { weight }(\mathrm{g} / 10 \mathrm{~g})\end{array}$ & Cooking time(mins) & Cooking loss(\%) \\
\hline Control $(10 \mathrm{~g})$ & $20.62 \pm 0.01^{\mathrm{a}}$ & $16 \pm 0.00^{\mathrm{a}}$ & $0.55 \pm 0.01^{\mathrm{a}}$ \\
\hline $50: 50$ & $22.10 \pm 0.01^{\mathrm{b}}$ & $17 \pm 0.00^{\mathrm{b}}$ & $1.08 \pm 0.01^{\mathrm{b}}$ \\
\hline $70: 30$ & $20.75 \pm 0.01^{\mathrm{c}}$ & $18 \pm 0.00^{\mathrm{c}}$ & $1.79 \pm 0.01^{\mathrm{c}}$ \\
\hline $90: 10$ & $18.03 \pm 0.01^{\mathrm{d}}$ & $19 \pm 0.00^{\mathrm{d}}$ & $1.81 \pm 0.01^{\mathrm{d}}$ \\
\hline
\end{tabular}

All values are means of triplicate determinations \pm standard deviation (SD)

Column followed by different letters are significantly different $(p<0.05)$ 
Table 6.Cooking quality of extruded product

\begin{tabular}{|l|l|l|}
\hline \multirow{2}{*}{ Sample } & \multicolumn{2}{|l|}{ Moisture content } \\
\cline { 2 - 3 } & Initial & Final \\
\hline Control & 14.18 & 5.63 \\
\hline $50: 50$ & 24.81 & 6.1 \\
\hline $70: 30$ & 21.56 & 6.4 \\
\hline $90: 10$ & 22.25 & 6.9 \\
\hline
\end{tabular}

All values are means of triplicate determinations \pm standard deviation (SD) Column followed by different letters are significantly different $(\mathrm{p}<0.05)$

Table 7.Initial and final moisture content of extruded product

\begin{tabular}{|c|c|c|c|}
\hline \multirow{2}{*}{ Samples } & \multicolumn{3}{|c|}{ Color values } \\
\cline { 2 - 4 } & $\mathbf{L}^{*}$ & $\mathbf{a}^{*}$ & $\mathbf{b}^{*}$ \\
\hline Control & $63.72 \pm 0.006^{\mathrm{a}}$ & $-0.91 \pm 0.01^{\mathrm{a}}$ & $10.53 \pm 0.00^{\mathrm{a}}$ \\
\hline $\mathbf{5 0 : 5 0}$ & $42.20 \pm 0.01^{\mathrm{b}}$ & $1.30 \pm 0.01^{\mathrm{b}}$ & $10.35 \pm 0.01^{\mathrm{b}}$ \\
\hline $\mathbf{7 0 : 3 0}$ & $39.50 \pm 0.01^{\mathrm{c}}$ & $1.84 \pm 0.01^{\mathrm{c}}$ & $9.86 \pm 0.01^{\mathrm{c}}$ \\
\hline $90: 10$ & $35.23 \pm 0.02^{\mathrm{d}}$ & $1.95 \pm 0.01^{\mathrm{d}}$ & $8.82 \pm 0.01^{\mathrm{d}}$ \\
\hline
\end{tabular}

Table 8.Nutrient composition of extrude product

\begin{tabular}{|l|l|l|c|}
\hline \multirow{2}{*}{ Nutrient Content } & Control & $\begin{array}{l}\text { Composite Millet } \\
\text { milk pasta }\end{array}$ & 't' value \\
\cline { 2 - 4 } & Mean \pm SD & Mean \pm SD & \\
\hline Protein(g) & $5.14 \pm 0.13$ & $7.37 \pm 0.32$ & $0.003^{*}$ \\
\hline Fat(g) & $0.013 \pm 0.005$ & $4.42 \pm 0.02$ & $0.000^{*}$ \\
\hline Carbohydrate(g) & $68.3 \pm 0.52$ & $58.84 \pm 0.005$ & $0.001^{*}$ \\
\hline Fiber(g) & - & $1.87 \pm 0.06$ & $0.000^{*}$ \\
\hline Ash(\%) & $1.00 \pm 0.00$ & $0.49 \pm 0.005$ & $0.000^{*}$ \\
\hline Iron(mg) & 1.0 & 1.5 & $0.000^{*}$ \\
\hline Calorificvalue (k.cal) & $293.3 \pm 0.58$ & $335.9 \pm 0.17$ & $0.000^{*}$ \\
\hline
\end{tabular}

All values are means of triplicate determinations \pm standard deviation (SD)

Column followed by different letters are significantly different $(p<0.05)$

Table 9.Amino acid composition of composite millet powder (g/100g of sample)

\begin{tabular}{|c|c|c|c|c|}
\hline Amino Acid Profile & Control & $\begin{array}{l}\text { Composite millet powder } \\
\text { g/100g }\end{array}$ & Mean increase & $\begin{array}{l}\mathrm{g} / \mathrm{kg} / \mathrm{d} \\
\text { FAO/WHO/UNU } \\
2007\end{array}$ \\
\hline \multicolumn{5}{|c|}{ Essential Amino Acids } \\
\hline Arginine & 0.36 & 0.40 & 0.04 & \\
\hline$\overline{\text { Histidine }}$ & 0.39 & 0.48 & 0.09 & 0.14 \\
\hline Isoleucine & 0.09 & 0.22 & 0.13 & 0.19 \\
\hline$\overline{\text { Leucine }}$ & 0.14 & 0.29 & 0.15 & 0.42 \\
\hline$\overline{\text { Lysine }}$ & 0.14 & 0.40 & 0.26 & 0.38 \\
\hline Methionine & 0.30 & 0.31 & 0.01 & 0.15 \\
\hline Phenylalanine & 0.79 & 0.79 & - & 0.25 \\
\hline Threonine & 0.43 & 0.88 & 0.45 & 0.02 \\
\hline$\overline{\text { Tryphtophan }}$ & 0.19 & 0.30 & 0.11 & 0.05 \\
\hline Valine & 0.08 & 0.20 & 0.12 & 0.24 \\
\hline$\overline{\text { Total }}$ & 2.91 & 4.27 & 1.36 & 1.84 \\
\hline
\end{tabular}




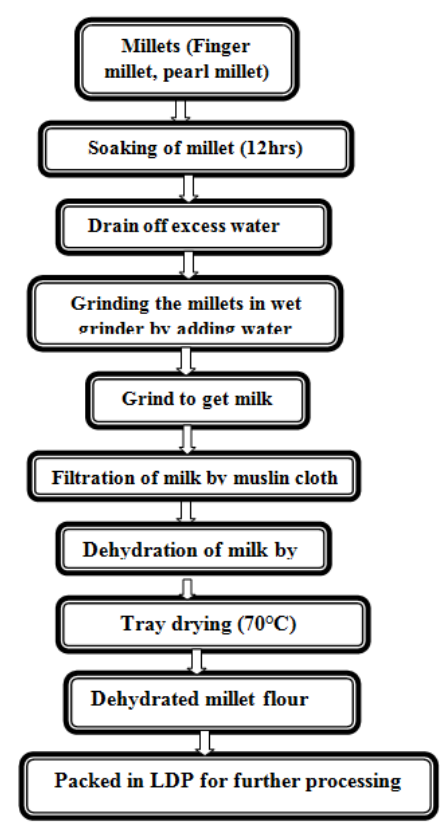

Fig 1: Steps involved in preparation of dehydrated composite millet powder

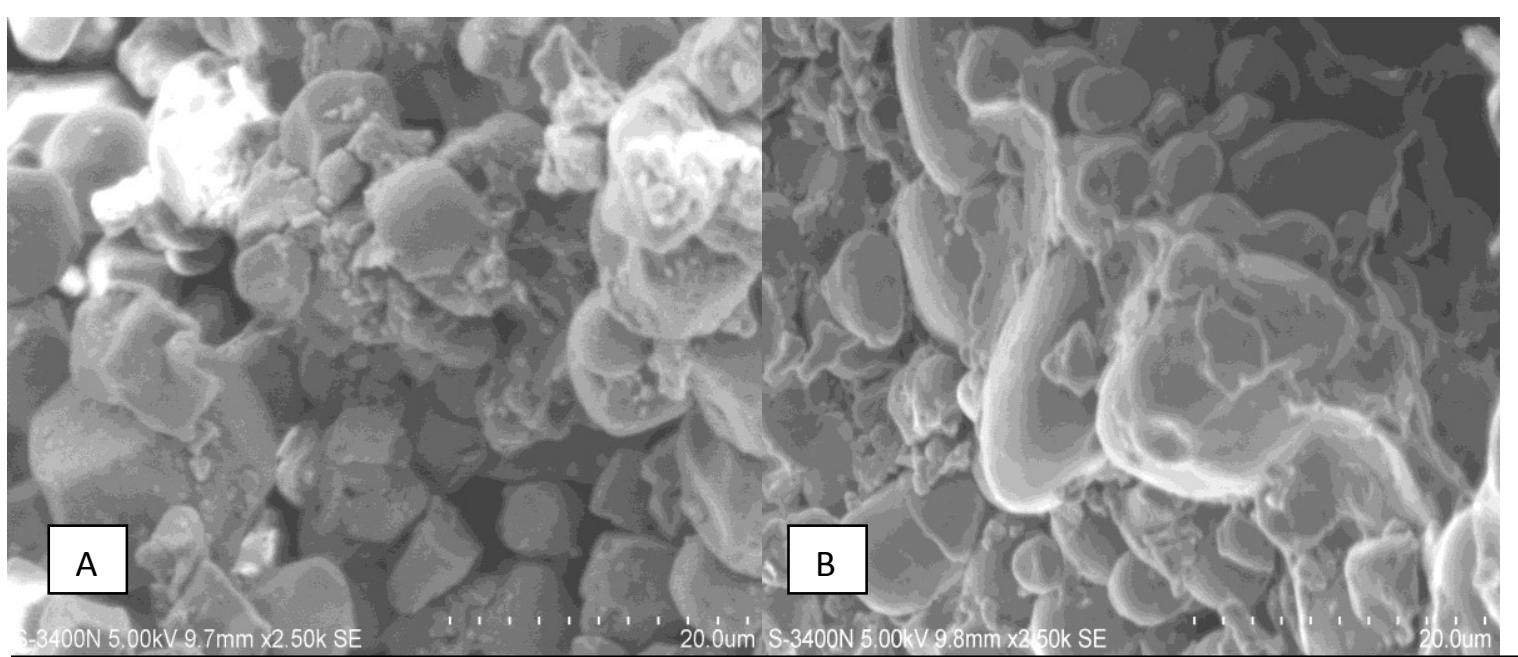

Fig 3. Morphology of (A) Composite millet milk powder and (B) Maida powder as measured by scanning electron microscopy at $1000 \mathrm{X}$

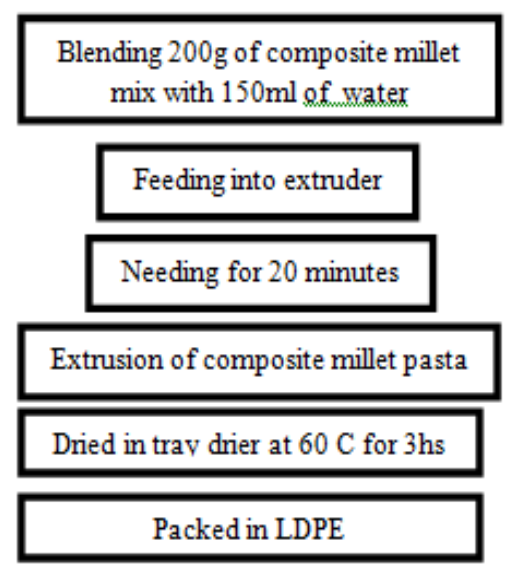

Fig 2 Process involved in the preparation of composite millet extruded product 